\title{
Hydrogen peroxide induced by the fungicide prothioconazole triggers deoxynivalenol (DON) production by Fusarium graminearum
}

\author{
Kris Audenaert ${ }^{1,2^{*}}$, Elien Callewaert ${ }^{1}$, Monica Höfte ${ }^{2}$, Sarah De Saeger ${ }^{3}$, Geert Haesaert ${ }^{1,2}$
}

\begin{abstract}
Background: Fusarium head blight is a very important disease of small grain cereals with $F$. graminearum as one of the most important causal agents. It not only causes reduction in yield and quality but from a human and animal healthcare point of view, it produces mycotoxins such as deoxynivalenol (DON) which can accumulate to toxic levels. Little is known about external triggers influencing DON production.

Results: In the present work, a combined in vivo/in vitro approach was used to test the effect of sub lethal fungicide treatments on DON production. Using a dilution series of prothioconazole, azoxystrobin and prothioconazole + fluoxastrobin, we demonstrated that sub lethal doses of prothioconazole coincide with an increase in DON production $48 \mathrm{~h}$ after fungicide treatment. In an artificial infection trial using wheat plants, the in vitro results of increased DON levels upon sub lethal prothioconazole application were confirmed illustrating the significance of these results from a practical point of view. In addition, further in vitro experiments revealed a timely hyperinduction of $\mathrm{H}_{2} \mathrm{O}_{2}$ production as fast as $4 \mathrm{~h}$ after amending cultures with prothioconazole. When applying $\mathrm{H}_{2} \mathrm{O}_{2}$ directly to germinating conidia, a similar induction of DON-production by $F$. graminearum was observed. The effect of sub lethal prothioconazole concentrations on DON production completely disappeared when applying catalase together with the fungicide.

Conclusions: These cumulative results suggest that $\mathrm{H}_{2} \mathrm{O}_{2}$ induced by sub lethal doses of the triazole fungicide prothioconazole acts as a trigger of DON biosynthesis. In a broader framework, this work clearly shows that DON production by the plant pathogen F. graminearum is the result of the interaction of fungal genomics and external environmental triggers.
\end{abstract}

\section{Background}

Fusarium graminearum is one of the main causal agents of Fusarium head blight (FHB) in small grain cereals [1]. Although FHB symptoms have a classical impact on yield, the major concern referred to FHB is the presence of mycotoxins. Fusarium spp. are able to produce a plethora of mycotoxins with diverse chemical and biological features [2]. This toxin fingerprint, inherent to the genetics of each individual strain, determines the chemotype of each particular Fusarium isolate. F. graminearum chemotypes are mainly characterized by type $\mathrm{B}$ trichothecenes among which deoxynivalenol (DON),

\footnotetext{
* Correspondence: kris.audenaert@hogent.be 'Department Biosciences and Landscape Architecture, Ghent University College/Ghent University Association, Schoonmeersstraat 52, B-9000 Gent, Belgium
}

(c) 2010 Audenaert et al; licensee BioMed Central Ltd. This is an Open Access article distributed under the terms of the Creative Commons Attribution License (http://creativecommons.org/licenses/by/2.0), which permits unrestricted use, distribution, and reproduction in any medium, provided the original work is properly cited. acetyldeoxynivalenol (3-ADON and 15-ADON) and nivalenol (NIV) are the most prevalent [3].

Although the genetic background of type B trichothecene production has been studied elaborately, a coherent view on the production profile of these mycotoxins during infection and colonization of a host is lacking and identifying or understanding mechanisms that regulate the production of these secondary metabolites remains a challenge [4-6]. To date, the role of the type $B$ trichothecene DON during infection and colonization of plants remains a controversial issue. Using DON nonproducing Fusarium strains, the importance of DON production during spread of the fungus throughout the grain host was demonstrated [4]. In concordance, DON production elicits defence responses in wheat [5]. This role for DON as a virulence factor, actively produced 
during the infection process, has been confirmed in many other studies [6-8]. Notwithstanding these compelling lines of evidence, other authors uncouple DON production from colonization and aggressiveness [9-11]. The aforementioned controversy illustrates nicely that besides the genotypical derived DON-chemotype, many environmental triggers are crucial to unequivocally delineate the DON-production by a strain of Fusarium. The involvement of external influences triggering DON production is further corroborated by research illustrating modulation of DON production by either abiotic factors such as $\mathrm{a}_{\mathrm{w}}$, temperature, available carbon and/or nitrogen source, and biotic factors such as presence of other fungi [12-16].

The importance of these external triggers in DON production is consolidated by the observation that the production level of mycotoxins in axenic in vitro cultures is often orders of magnitude lower than observed during infection and colonization of a host, suggesting that specific host signals are involved in eliciting mycotoxins production. The secondary plant signalling compound hydrogen peroxide $\left(\mathrm{H}_{2} \mathrm{O}_{2}\right)$, which is involved in plantfungi interactions, is highlighted as an possible trigger interfering with type B trichothecene production. In previous work with $F$. graminearum, it was demonstrated that exogenously applied $\mathrm{H}_{2} \mathrm{O}_{2}$ at time of spore germination resulted in higher DON and A-DON levels 30 days later [17]. In addition, this DON accumulation was accompanied by an up-regulation of the tri gene machinery, responsible for DON biosynthesis $[18,19]$. Moreover, liquid cultures of $F$. graminearum supplied with $\mathrm{H}_{2} \mathrm{O}_{2}$ started to produce $\mathrm{H}_{2} \mathrm{O}_{2}$ themselves and the kinetics of this paralleled with DON accumulation [19] indicating a link between DON production and oxidative stress. Notwithstanding this clear observation, underlying mechanisms remain elusive. Recently, evidence is brought forward that the response of Fusarium to $\mathrm{H}_{2} \mathrm{O}_{2}$ is chemotype dependent. Ponts et al. (2009) observed a reduced NIV production in these chemotypes upon exogenous $\mathrm{H}_{2} \mathrm{O}_{2}$ application while the opposite was observed in DON chemotypes. Furthermore these data suggest that NIV isolates combine this adaptation to oxidative stress with a proliferated virulence [20].

The application of fungicides as possible external triggers for thrichothecene biosynthesis remains a controversial issue. Several authors have described that sublethal concentrations of fungicides trigger thrichothecene biosynthesis [21-23]. Others report opposite results $[24,25]$.

The objective of the present work, was to investigate the influence of three fungicides i.e. prothioconazole (a triazole fungicide), azoxystrobin (a strobilurin fungicide) and prothioconazole + fluoxastrobin, applied at sub lethal concentrations on DON production by F. graminearum.
Triazoles are known inhibitors of the ergosterol biosynthesis in fungi while strobilurin fungicides inhibit mitochondrial electron transport by binding the Qo site of cytochrome bc1 complex. Where the effectiveness of triazole fungicides against Fusarium spp. is a certainty, the activity of strobilurins against Fusarium spp. is doubtable.

The hypothesis of a fungicide-induced oxidative stress response as a trigger for DON biosynthesis was evaluated by a combined approach of $\mathrm{H}_{2} \mathrm{O}_{2}$ measurements and application of the $\mathrm{H}_{2} \mathrm{O}_{2}$ scavenger enzyme catalase. Finally, the work was validated on a laboratory scale in an in vivo assay using wheat plants. The present work clearly demonstrates the risks of reduced fungicide doses with respect to DON accumulation.

\section{Results}

Effectiveness of fungicides to inhibit conidial germination and to reduce fungal biomass

Strobilurins and triazoles are among the most frequently used fungicides to respectively control $M$. nivale and F. graminearum. Nevertheless, application of these chemicals is often suboptimal due to the short vulnerable period of the pathogen in the field (during anthesis of the host), and environmental factors such as rain and wind. To determine if suboptimal fungicide treatments influence germination of $F$. graminearum conidia and DON production, an in vitro assay was set up using a dilution series of azoxystrobin, prothioconazole and fluoxastrobin + prothioconazole. Azoxystrobin did not influence the F. graminearum conidial germination at any of the given time points in a concentrationdependent way (Figure 1C). In contrast, prothioconazole effectively inhibited conidial germination at field dose and in dilutions $1 / 10$ and $1 / 100$ but did not have a significant effect at lower doses at time point $48 \mathrm{~h}$ (Figure 1B). At time intervals $4 \mathrm{~h}$ and $24 \mathrm{~h}$, intermediate concentrations caused a temporary delay in germination. Finally the combination of prothioconazole and fluoxastrobin exhibited fungicidal activity at field concentration and inhibited germination in dilutions $1 / 100$ and $1 / 100$ and displayed no or very little effect in dilution $1 / 1000$ (Figure 1A). Similar results were observed at the level of mycelial radial outgrowth (data not shown).

The effect of the different fungicides on conidial germination was also reflected in the amount of fungal biomass as measured by Q-PCR analysis (Table 1). These Q-PCR data clearly highlighted an effect of prothioconazole and protioconazole + fluoxastrobin on Fusarium growth.

\section{Effect of fungicides on DON production}

To check whether the effect of the strobilurin fungicides and the triazole fungicide prothioconazole on fungal 


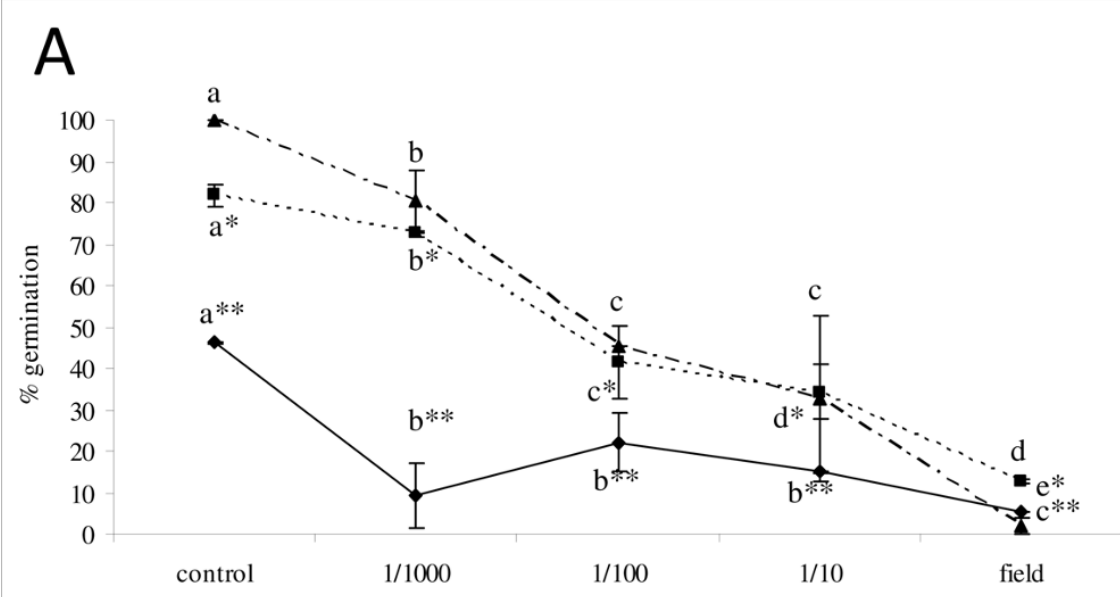

B

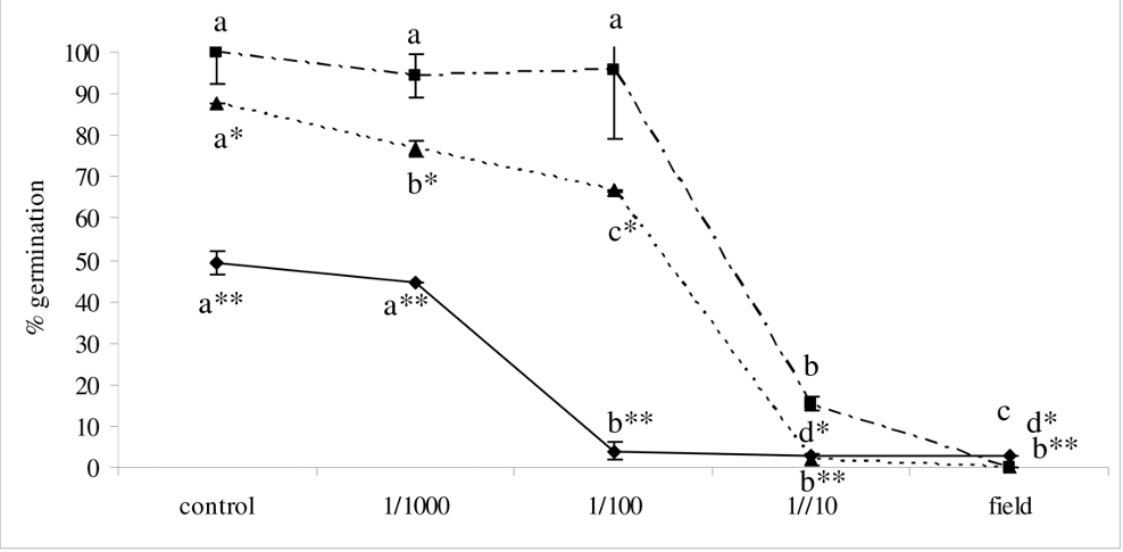

C

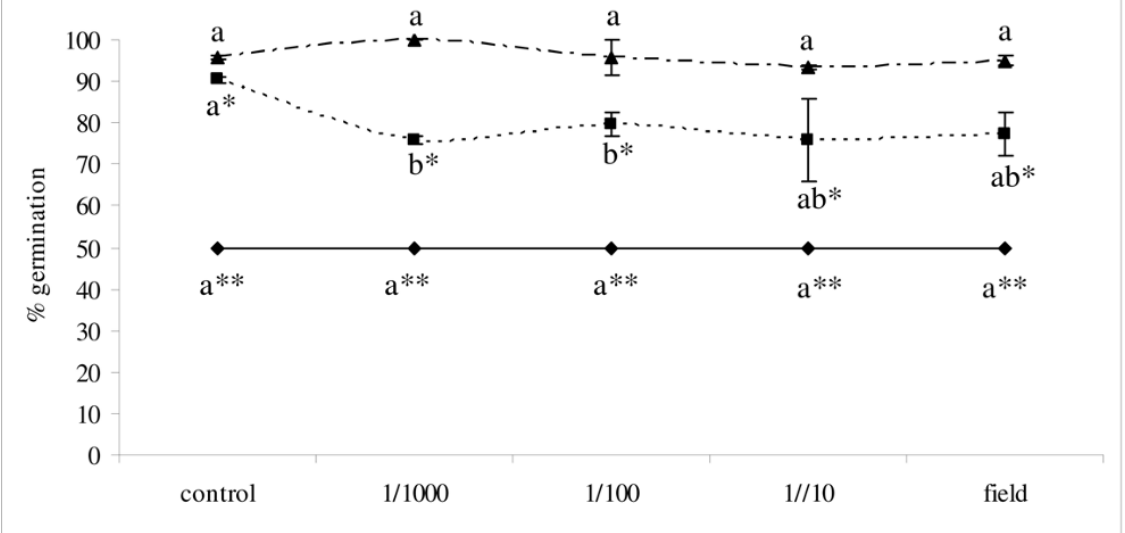

Figure 1 Effect of prothioconazole + fluoxastrobin (a), prothioconazole (b) and azoxystrobin (c) on conidial germination of $F$. graminearum. Conidia at a concentration of $10^{6} \mathrm{conidia} / \mathrm{ml}$ were challenged with a tenfold dilution series of fluoxastrobin + prothioconazole, azoxystrobin and prothioconazole starting from $0.5 \mathrm{~g} / \mathrm{l}+0.5 \mathrm{~g} / \mathrm{l}, 0.83 \mathrm{~g} / \mathrm{l}$ and $0.67 \mathrm{~g} / \mathrm{l}$. For each treatment and repetition 50 conidia were scored for their germination and percentage of conidial germination was calculated at $4 \mathrm{~h}$ (solid line), $24 \mathrm{~h}$ (dashed line) and $48 \mathrm{~h}$ (point dashed line) after staining with $0.02 \%$ of cotton blue in lactic acid. Experiment consisted of two repetitions for each treatment and the experiment was repeated three times. Graphs represent the average of all three experiments. Different letters at each data point indicate differences from the control treatment at $4 \mathrm{~h} \mathrm{(**)}, 24 \mathrm{~h} \mathrm{(*)}$ and $48 \mathrm{~h}$ after analysis with a Kruskall-Wallis and Mann-Whitney test with a sequential Bonferroni correction for multiple comparisons. 
Table 1 Effect of a tenfold dilution series of prothioconazole, prothioconazole + fluoxastrobin and azoxystrobin on fungal biomass measured by Q-PCR analysis.

\begin{tabular}{lllllll}
\hline & prothio & prothio+catalase* & prothio+fluoxa & prothio+fluoxa+catalase* $^{*}$ & azoxy & azoxy+catalase* \\
\hline control & $235.68^{\mathrm{a}}$ & $194.60^{\mathrm{a}}$ & $255.68^{\mathrm{a}}$ & $245.89^{\mathrm{a}}$ & $251.57^{\mathrm{a}}$ & $232.45^{\mathrm{a}}$ \\
$1 / 1000$ & $9.42^{\mathrm{b}}$ & $63.03^{\mathrm{b}}$ & $76.23^{\mathrm{b}}$ & $48.17^{\mathrm{b}}$ & $267.16^{\mathrm{a}}$ & $230.12^{\mathrm{a}}$ \\
$1 / 100$ & $2.35^{\mathrm{c}}$ & $31.13^{\mathrm{c}}$ & $16.58^{\mathrm{c}}$ & $44.90^{\mathrm{b}}$ & $250.01^{\mathrm{a}}$ & $234.93^{\mathrm{a}}$ \\
$1 / 10$ & $2.51^{\mathrm{c}}$ & $50.02^{\mathrm{bc}}$ & LD & LD & $254.22^{\mathrm{a}}$ & $216.00^{\mathrm{a}}$ \\
field & LD & $33.47^{\mathrm{c}}$ & LD & LD & $236.54^{\mathrm{a}}$ & $170.72^{\mathrm{a}}$ \\
\hline
\end{tabular}

F. graminearum biomass expressed as $\mathrm{ng} / \mu \mathrm{l}$. In each run, a no-template control was included. The amount of fungal material was measured based on a standard series of $F$. graminearum DNA ranging from $100 \mathrm{ng} / \mu \mathrm{l}$ down to $3.125 \mathrm{ng} / \mu \mathrm{l}$ which was carried out in triplicate.

Different letters indicate significant differences after analysis with a Kruskall-Wallis Mann-Whitney analysis with $P=0.05$

Prothio: prothioconazole; azoxy: azoxystrobin; fluoxa:fluoxastrobin

*: Effect of catalase $(1000 \mathrm{U} / \mathrm{ml})$ added at the start of the experiment on the $F$. graminearum biomass.

LD: Lower than detection limit.

biomass and germination was paralleled by a reduced production of the type B trichothecene DON, levels of this mycotoxin were measured using a competitive ELISA-approach (Figure 2A, B, C). As expected, application of azoxystrobin did not influence DON production by $F$. graminearum strain $8 / 1$. Remarkably, the combined application of prothioconazole and fluoxastrobin triggered a huge production of DON at the sub lethal doses of dilution $1 / 10$ and $1 / 100$, as early at time point $48 \mathrm{~h}$ but not at earlier time points $(4 \mathrm{~h}$ and $24 \mathrm{~h}$, data not shown). For the sole application of prothioconazole no major effects on DON production were observed since none of the tested concentrations were sub lethal. In an additional experiment using an extra intermediate concentration of $1 / 50$ of the field concentration of prothioconazole, a reduced spore germination of about $50 \%$ was observed (data not shown). Concomitant with this observation, this sub lethal dilution resulted in an increased DON production (32 $\mu \mathrm{g} / \mu \mathrm{g}$ of fungal DNA). Hence, application of sub lethal concentrations of respectively prothioconazole + fluoxastrobin and prothioconazole seems to result in the activation of the trichothecene biosynthesis machinery leading to an accumulation of DON as fast as $48 \mathrm{~h}$ after the start of the experiment.

\section{Timely production of $\mathrm{H}_{2} \mathrm{O}_{2}$ precedes DON accumulation} in combined strobilurin and triazole fungicide application As several lines of evidence in literature corroborate an important role for reactive oxygen species (ROS) and more specifically $\mathrm{H}_{2} \mathrm{O}_{2}$ in stress responses of fungi, the accumulation of $\mathrm{H}_{2} \mathrm{O}_{2}$ upon fungicide application was monitored in the established in vitro germination assay. In these experiments, we unequivocally demonstrated that sole application of respectively azoxystrobin and prothioconazole at the given concentrations did not result in elevated $\mathrm{H}_{2} \mathrm{O}_{2}$ concentrations at any of the time points (Figure 3). In addition, prothioconazole at field dose resulted in lower $\mathrm{H}_{2} \mathrm{O}_{2}$ concentrations than those observed in control samples possibly reflecting the reduction in microbial metabolic activity due to the application of the fungicide. Sub lethal dilutions of the combined application of fluoxastrobin + prothioconazole (i.e. $1 / 10$ and $1 / 100$ ) resulted in an increased $\mathrm{H}_{2} \mathrm{O}_{2}$ content in the medium compared to the control and the other treatments as fast as $4 \mathrm{~h}$ after the start of the germination assay. Although the increase at concentration $1 / 100$ was less proliferate than the increase at concentration $1 / 10$ of the field dose of fluoxastrobin + prothioconazole, it was consistent in all performed experiments. Moreover, this peak in $\mathrm{H}_{2} \mathrm{O}_{2}$ disappeared or was less proliferated at later time points $24 \mathrm{~h}$ and $48 \mathrm{~h}$. These findings strongly suggest that timely production of $\mathrm{H}_{2} \mathrm{O}_{2}$ triggers the trichothecene biosynthesis machinery to produce DON in sub lethal fungicide treatments.

To further examine the role of $\mathrm{H}_{2} \mathrm{O}_{2}$ in fungicideinduced stress, exogenous catalase was added together with the fungicidal treatment. At $4 \mathrm{~h}$ after application, catalase resulted in a reduced germination rate (Figure 4A, B) compared to all non-catalase treatments. In addition, at later time points, the application of catalase partially abolished the fungicidal effect of prothioconazole + fluoxastrobin (Figure 4C) and of prothioconazole (Figure 4D) at both the level of conidial germination and fungal biomass (Table 1). No effect was observed in the treatment with azoxystrobin (data not shown). In addition, this partial loss of fungicidal effect due to the application of catalase was accompanied by the disappearance of the $\mathrm{H}_{2} \mathrm{O}_{2}$ peak previously observed in the prothioconazole + fluoxastrobin treated samples at $4 \mathrm{~h}$ after application of prothioconazole (Figure 5A). No peak was observed in the treatment with sole application of prothioconazole (Figure 5B). At later time points, no $\mathrm{H}_{2} \mathrm{O}_{2}$ accumulation was observed in none of the treatments (data not shown). Finally, completely in line with these observations, the disappearance of the $\mathrm{H}_{2} \mathrm{O}_{2}$ trigger at $4 \mathrm{~h}$ due to the application of catalase resulted in DON production comparable to control treatments (Figure 2D, E, F). 

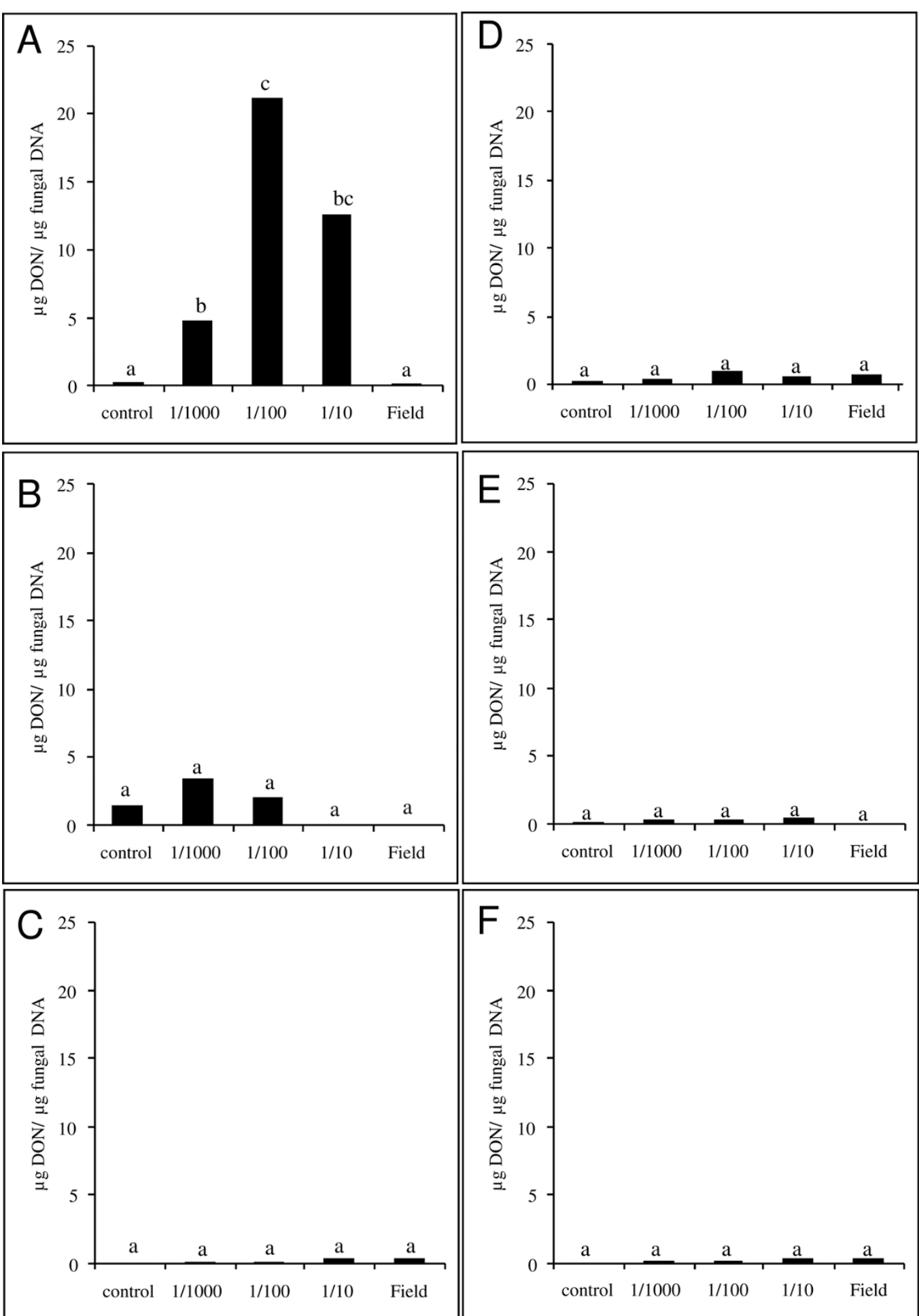

Figure 2 Effect of prothioconazole + fluoxastrobin (a), prothioconazole (b) and azoxystrobin (c) alone or in combination with catalase $(\mathbf{d}, \mathbf{e}, \mathbf{f})$ on production of deoxynivalenol (DON) by F. graminearum. Conidia at a concentration of $10^{6} \mathrm{conidia} / \mathrm{ml}$ were challenged with a tenfold dilution series of fluoxastrobin + prothioconazole, azoxystrobin and prothioconazole starting from $0.5 \mathrm{~g} / \mathrm{l}+0.5 \mathrm{~g} / \mathrm{l}, 0.83 \mathrm{~g} / \mathrm{l}$ and $0.67 \mathrm{~g} / \mathrm{l}$ in absence $(a, b, c)$ or presence $(e, f, g)$ of $1000 \mathrm{U} / \mathrm{ml}$ catalase. DON content in the medium was determined using a competitive ELISA approach $48 \mathrm{~h}$ after start of the experiments. Each bar is the result of two pooled samples to reduce variance. The experiment was repeated twice in time of which one representative experiment is shown in the figure. Different letters above bars indicate significant differences after analysis with a Kruskall-Wallis and Mann-Whitney test with a sequential Bonferroni correction for multiple comparisons. 

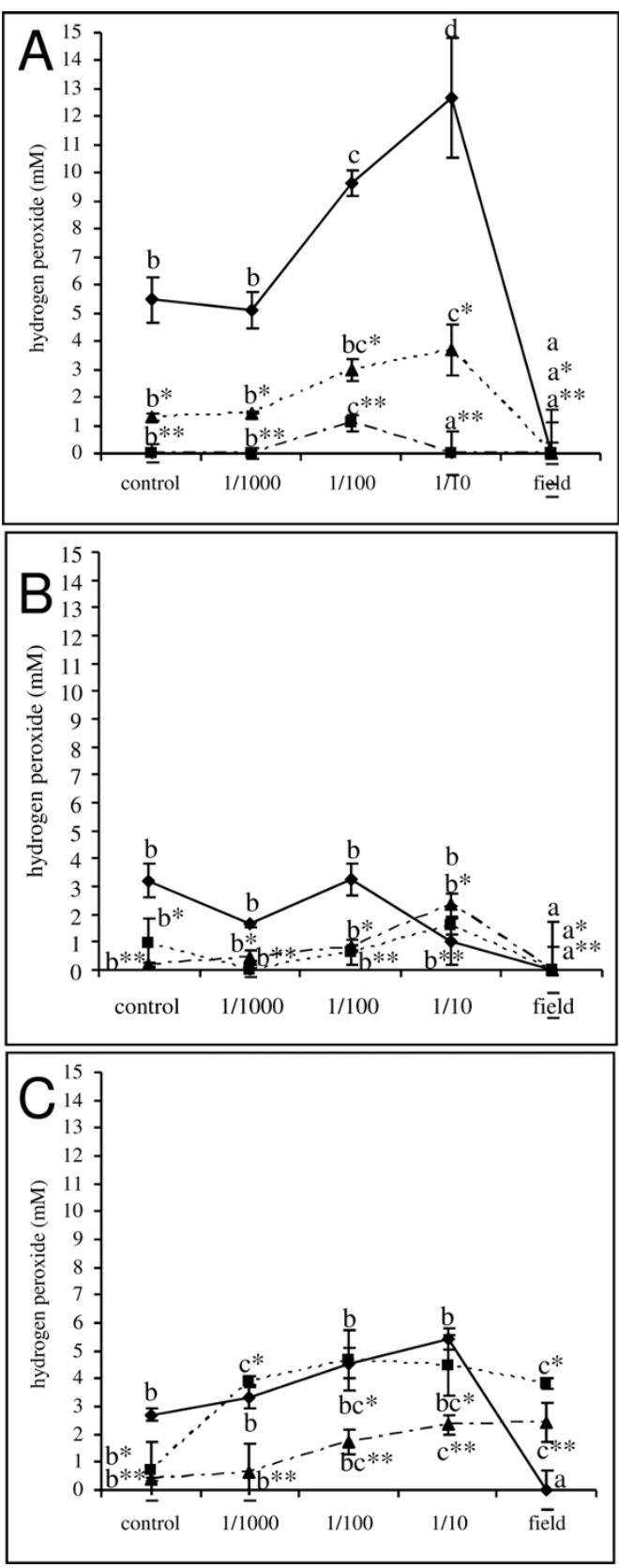

Figure 3 Effect of prothioconazole + fluoxastrobin (a), prothioconazole (b) and azoxystrobin (c) on extracellular $\mathrm{H}_{2} \mathrm{O}_{2}$ concentrations. Conidia at a concentration of $10^{6}$ conidia $/ \mathrm{ml}$ were challenged with a tenfold dilution series of fluoxastrobin + prothioconazole, azoxystrobin and prothioconazole starting from $0.5 \mathrm{~g} / \mathrm{l}+0.5 \mathrm{~g} / \mathrm{l}, 0.83 \mathrm{~g} / \mathrm{l}$ and $0.67 \mathrm{~g} / \mathrm{l} . \mathrm{H}_{2} \mathrm{O}_{2}$ was measured at $4 \mathrm{~h}$ (solid line), $24 \mathrm{~h}$ (dashed line) and $48 \mathrm{~h}$ (point dashed line) using TMB (trimethylbenzidine) as a substrate in the presence of an overdose of peroxidase. The $\mathrm{H}_{2} \mathrm{O}_{2}$ concentrations were calculated based on a standard curve included in each experiment. Each data point is the result of three repetitions and the experiments were repeated twice in time. Different letters at each data point indicate differences from the control treatment at $4 \mathrm{~h}\left(^{* *}\right), 24 \mathrm{~h}\left({ }^{*}\right)$ and $48 \mathrm{~h}$ after analysis with a Kruskall-Wallis and Mann-Whitney test with a sequential Bonferroni correction for multiple comparisons.
Stress-induced $\mathrm{H}_{2} \mathrm{O}_{2}$ accumulation upon fungicide application is necessary and sufficient as a trigger to induce DON

To further decipher a direct link between $\mathrm{H}_{2} \mathrm{O}_{2}$ at one hand and the production of the mycotoxin DON at the other hand, the accumulation of DON was monitored upon exogenously single pulse application of $\mathrm{H}_{2} \mathrm{O}_{2}$ ranging from $0.01 \mathrm{mM}$ up to $100 \mathrm{mM} . \mathrm{H}_{2} \mathrm{O}_{2}$ influenced germination of $F$. graminearum conidia in a concentration-dependent manner (Figure 6). As early as $4 \mathrm{~h}$ after the start of the assay, exogenously application of $\mathrm{H}_{2} \mathrm{O}_{2}$ at concentrations from $1 \mathrm{mM}$ up to $100 \mathrm{mM}$ retarded or stopped conidial germination. The sub lethal concentration of $10 \mathrm{mM} \mathrm{H}_{2} \mathrm{O}_{2}$ induced DON production as fast as $4 \mathrm{~h}$ after application of $\mathrm{H}_{2} \mathrm{O}_{2}$ in one of the experiments. In the other experiment, $4 \mathrm{~h}$ was probably just too early to observe the increased DON production and in this experiment, the increment in DON was observed at $24 \mathrm{~h}$. The ability of $10 \mathrm{mM} \mathrm{H}_{2} \mathrm{O}_{2}$ to initiate DON production is in concordance with $\mathrm{H}_{2} \mathrm{O}_{2}$ concentrations induced by sub lethal prothioconazole concentrations (Figure 3A). At later time points, DON did not further accumulate and concentration remained the same for the subsequent 24 and $48 \mathrm{~h}$ time points. This effect of $\mathrm{H}_{2} \mathrm{O}_{2}$ on DON production was confirmed by an experiment in which $\mathrm{H}_{2} \mathrm{O}_{2}$ was eliminated from the well plates by exogenously applied catalase. This resulted in a fall-back of the DON production in the $10 \mathrm{mM} \mathrm{H}_{2} \mathrm{O}_{2}$ treatment to levels comparable to control wells (data not shown). Finally, surprisingly, low concentrations of $\mathrm{H}_{2} \mathrm{O}_{2}$ facilitated conidial germination compared to control samples. Indicating the necessity of low levels of $\mathrm{H}_{2} \mathrm{O}_{2}$ in optimal germination of conidia and proliferation of fungal cells.

\section{Sublethal prothioconazole + fluoxastrobin application triggers DON production in vivo}

In an in vivo case study with azoxystrobin and prothioconazole + fluoxastrobin, the effect of sub lethal fungicide concentrations on growth and DON production was verified on wheat plants (variety Cadenza) during anthesis. A point inoculation with $F$. graminearum clearly led to typical Fusarium symptoms 14 days after inoculation (Figure 7). In the treatment with azoxystrobin, no reduction of symptoms was observed (data not shown) which is in concordance with the previously described in vitro data. Application of prothioconazole + fluoxastrobin resulted in a complete control of Fusarium at field dose or dilution 1/10 (Figure 7A). At concentration $1 / 100$ symptoms were apparent although they were less proliferate than in the inoculated control plants pointing to a sub lethal concentration. Parallel with the symptom evaluation, DON content was determined in the wheat ears. No DON was apparent in treatments 


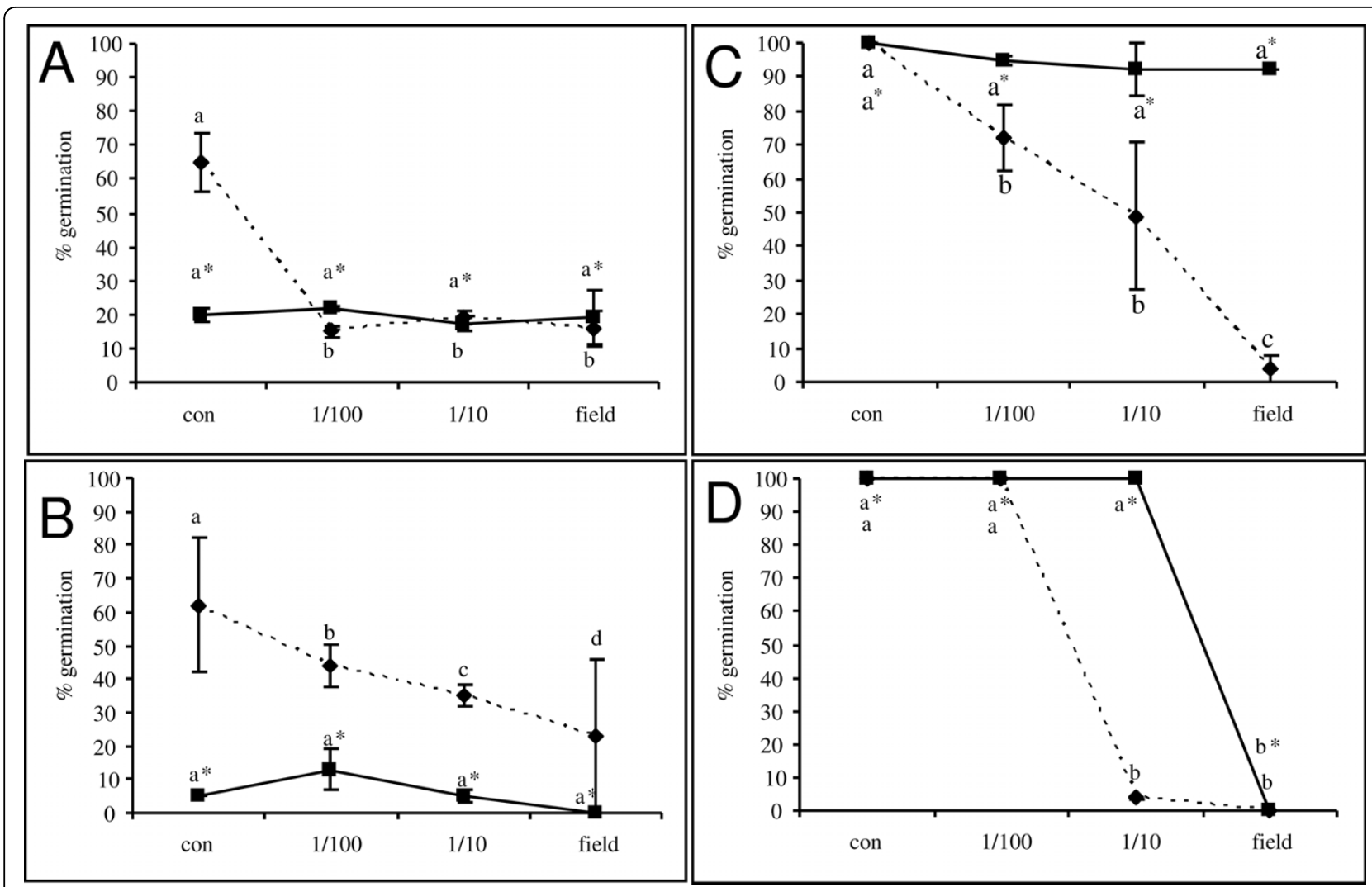

Figure 4 Effect of prothioconazole + fluoxastrobin $(a, c)$ and prothioconazole $(b, d)$ in absence (dashed line) or presence (solid line) of exogenous catalase on the germination of $F$. graminearum conidia after $\mathbf{4} \mathbf{h}(\mathbf{a}, \mathbf{b})$ and $\mathbf{4 8} \mathbf{h}(\mathbf{c}, \mathbf{d})$. Conidia at a concentration of $10 e^{6}$ were challenged with a tenfold dilution series of fluoxastrobin + prothioconazole, azoxystrobin and prothioconazole starting from $0.5 \mathrm{~g} / \mathrm{l}+0.5 \mathrm{~g} / \mathrm{l}$, $0.83 \mathrm{~g}$ and $0.67 \mathrm{~g} / \mathrm{l}$. At the beginning of the experiment, catalase $(1000 \mathrm{U} / \mathrm{ml})$ was added to the germinating conidia. For each treatment and repetition 50 conidia were scored for their germination after staining with $0.02 \%$ of cotton blue in lactic acid and percentage of conidial germination was calculated. This experiment was repeated twice in time. Different letters at each data point indicate differences from the control treatment after analysis with a Kruskall-Wallis and Mann-Whitney test with a sequential Bonferroni correction for multiple comparisons.

with field dose or dilution $1 / 10$. However, a significant increase in DON content was observed in ears originating from the $1 / 100$ treatment compared to the control treatment (Figure 7B) which is in concordance with the in vitro observations.

\section{Discussion}

In an effort to broaden our understanding of external triggers influencing the DON production machinery of F. graminearum, the effect of strobilurin and triazole fungicides on DON production was investigated. Our results demonstrate that prothioconazole, a triazole fungicide, has good control capacities culminating in reduced vegetative radial outgrowth, a reduced conidial germination and a reduction of $F$. graminearum biomass. Triazoles are known inhibitors of the ergosterol biosynthesis in fungi and have been described for their good control capacities against Fusarium spp [21].

On the contrary, the strobilurin fungicide azoxystrobin was not able to induce a reduction in radial outgrowth, spore germination and fungal biomass. Strobilurin fungicides inhibit mitochondrial electron transport by binding the Qo site of cytochrome bc1 complex. Although the effectiveness of strobilurins against Fusarium spp. is doubtable, they have been reported to be effective against $F$. culmorum [24] Apparently, F. graminearum is very resistant to this type of fungicides. Resistance to strobilurin fungicides has been reported in many species to be associated with a single amino acid replacement at position 143 of the cytochrome $b$ gene [26-28]. Although this mechanism was recently described in Microdochium nivale it has not yet been described in F. graminearum. We assume that the observed resistance is therefore possibly a consequence of the activation of a respiratory chain using an alternative oxidase (AOX) bypassing complexes III and IV in the cytochrome mediated pathway. Activity of this AOX mediates electron transfer directly from ubiquinol to oxygen. Kaneko and Ishii (2009) demonstrated that F. graminearum acts very rapidly upon strobilurin application by 


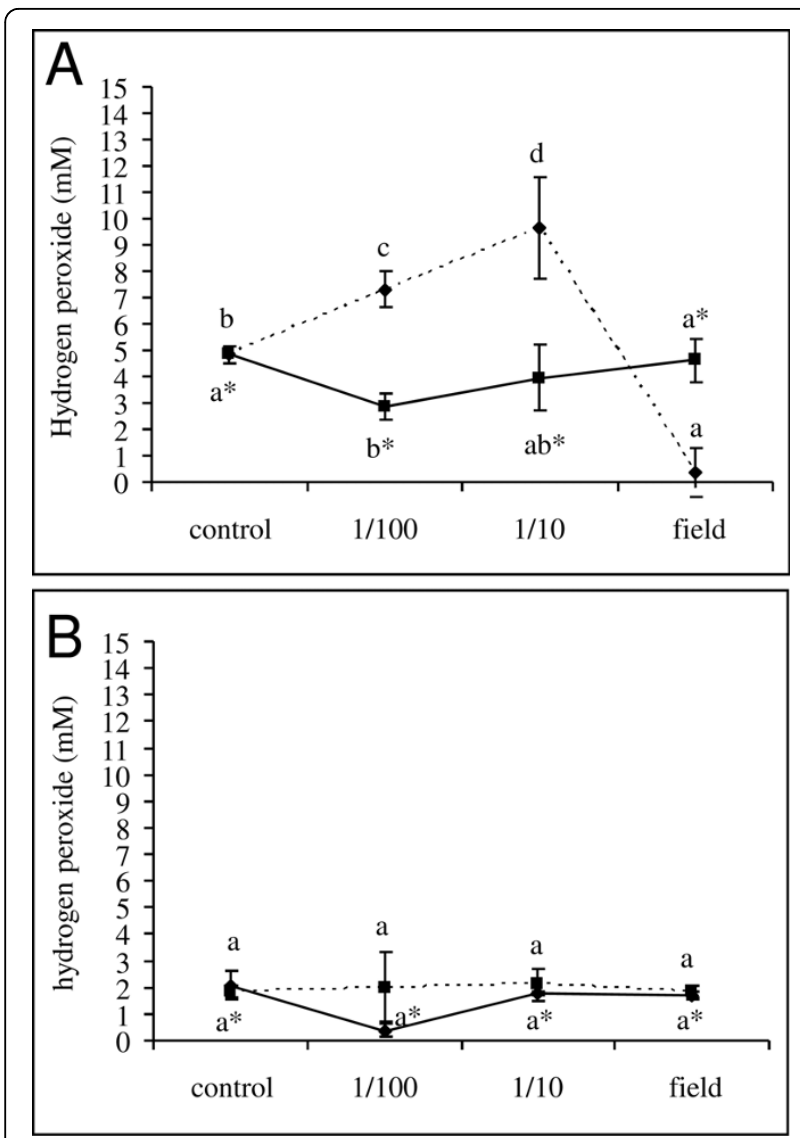

Figure 5 Effect of a combined application of catalase and respectively prothioconazole + fluoxastrobin (a) and prothioconazole (b) on extracellular $\mathrm{H}_{2} \mathrm{O}_{2}$ concentrations at $4 \mathrm{~h}$ after fungicide application. Conidia at a concentration of $10^{6}$ conidia/ml were challenged with a tenfold dilution series of fluoxastrobin + prothioconazole, azoxystrobin and prothioconazole starting from $0.5 \mathrm{~g} / \mathrm{l}+0.5 \mathrm{~g} / \mathrm{l}, 0.83 \mathrm{~g}$ and $0.67 \mathrm{~g} / \mathrm{l}$ in the absence (dashed line) or presence of $1000 \mathrm{U} / \mathrm{ml}$ catalase (solid line). $\mathrm{H}_{2} \mathrm{O}_{2}$ was measured at $4 \mathrm{~h}$ using TMB (trimethylbenzidine) as a substrate in the presence of an overdose of peroxidase. The $\mathrm{H}_{2} \mathrm{O}_{2}$

concentrations were calculated based on a standard curve included in each experiment. Each data point is the result of three repetitions and the experiments were repeated twice in time. Different letters at each data point indicate differences from the control treatment after analysis with a Kruskall-Wallis and Mann-Whitney test with a sequential Bonferroni correction for multiple comparisons.

the activation of AOX whereas $M$. nivale, a fungal species susceptible to strobilurins, reacted slowly with a retarded moderate activation of this enzyme [29].

Since the generation of reactive oxygen species such as $\mathrm{H}_{2} \mathrm{O}_{2}$ is a hallmark of an oxidative stress response, extracellular $\mathrm{H}_{2} \mathrm{O}_{2}$ was measured upon fungicide application in an in vitro assay. Unexpectedly, application of strobilurin fungicides did not result in an increased extracellular $\mathrm{H}_{2} \mathrm{O}_{2}$ formation, which is at first sight, contradictory to previous findings by Kaneko and Ishii (2009) who found an increased production of $\mathrm{H}_{2} \mathrm{O}_{2}$ upon strobilurin application. However it is important to notice that in the present work the $\mathrm{H}_{2} \mathrm{O}_{2}$ released in the medium was measured whereas Kaneko and Ishii (2009) focused on intracellular $\mathrm{H}_{2} \mathrm{O}_{2}$. Remarkably, the application of sub lethal doses of prothioconazole or the combination of prothioconazole amended with fluoxastrobin resulted in a boosted $\mathrm{H}_{2} \mathrm{O}_{2}$ production as fast as $4 \mathrm{~h}$ after application. This prompt production disappeared at later time points. In addition, a clear induction of DON production was observed $48 \mathrm{~h}$ after application of sub lethal prothioconazole + fluoxastrobin concentrations. This induction of DON was confirmed in an in vivo experiment in which flowering wheat plants were infected with $F$. graminearum and subjected to a sub lethal dose of prothioconazole + fluoxastrobin. Previous work on $F$. culmorum demonstrated no or a negative effect of several strobilurins and triazoles on DON production [24] so the observed phenomenon of an increased DON production by F. graminearum induced by sub lethal concentrations of triazole fungicides might be a strain- or species-specific phenomenon.

It is tempting to speculate whether this accumulation of DON is the consequence of the preceding accumulation of $\mathrm{H}_{2} \mathrm{O}_{2}$ as such being the first link in a signalling cascade activated upon sub lethal triazole treatment. Although this key role of $\mathrm{H}_{2} \mathrm{O}_{2}$ is not unambiguously demonstrated in the present study, the amount of evidence is compelling: $\mathrm{H}_{2} \mathrm{O}_{2}$ precedes accumulation of DON, combined application of catalase (eliminating $\mathrm{H}_{2} \mathrm{O}_{2}$ from the medium) inhibited DON accumulation. In addition, the application led to a reduced activity of the triazole fungicide. Application of $\mathrm{H}_{2} \mathrm{O}_{2}$ to F. graminearum cultures led to a reduced germination and prompt induction of DON biosynthesis $4 \mathrm{~h}$ after $\mathrm{H}_{2} \mathrm{O}_{2}$ application. This additional experiment proves that $\mathrm{H}_{2} \mathrm{O}_{2}$ accumulation is necessary and sufficient to initiate DON production. The activation of the DON biosynthesis machinery by $\mathrm{H}_{2} \mathrm{O}_{2}$ is in concordance with previous observations by the group of Barreau $[17,19,20]$ who demonstrated that exogenously applied $\mathrm{H}_{2} \mathrm{O}_{2}$ by repeated single or pulse-feeding resulted in accumulation of DON. However, these authors only monitored increases in DON at late time points such as 10 to 30 days after $\mathrm{H}_{2} \mathrm{O}_{2}$ application whereas we observe a clear prompt activation of DON production within hours. From a physiological point of view the effect of $\mathrm{H}_{2} \mathrm{O}_{2}$ during the initial germination events is logic and in line with the physiology of an in field $F$. graminearum infection: $\mathrm{H}_{2} \mathrm{O}_{2}$ is one of the key regulators in the plant defense system upon pathogen attack [30]. Therefore, this molecule is encountered frequently and at early time points by the pathogen in the interaction with its host. Previous work by the group of John Manners demonstrated beautifully that DON itself can induce 

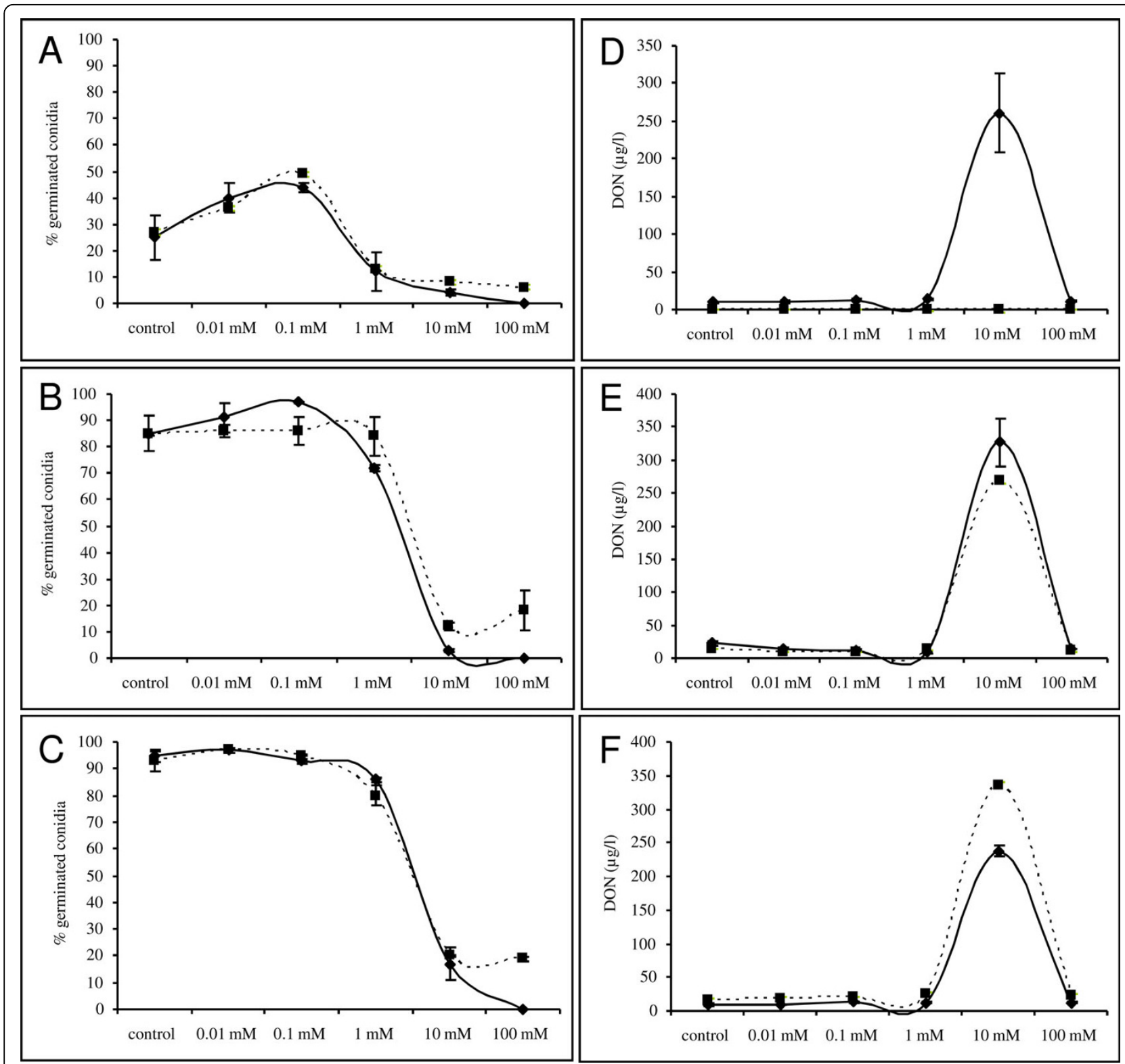

Figure 6 Effect of exogenously applied $\mathrm{H}_{2} \mathrm{O}_{2}$ on germination $(a, b, c)$ of $F$. graminearum and DON production (d,e,f) after $4 \mathrm{~h}(\mathrm{a}$ and d), $24 \mathbf{~ h ~ ( b ~ a n d ~ e ) ~ a n d ~} \mathbf{4 8} \mathbf{~ h ~ ( c ~ a n d ~ f ) . ~ C o n i d i a ~ a t ~ a ~ c o n c e n t r a t i o n ~ o f ~} 10^{6}$ conidia/ml were challenged with a tenfold dilution series of $\mathrm{H}_{2} \mathrm{O}_{2}$. For each treatment and repetition 50 conidia were scored for their germination after staining with $0.02 \%$ of cotton blue in lactic acid and percentage of conidial germination was calculated. DON content in the medium was determined using a competitive ELISA approach. Each treatment was measured in duplicate and the experiment was repeated twice in time (dashed and solid line represent the two experiments).

hypersensitive cell death and $\mathrm{H}_{2} \mathrm{O}_{2}$ during infection [5] and as such underpinning the interaction between both molecules.

Astonishingly, very low concentrations of $\mathrm{H}_{2} \mathrm{O}_{2}$ promoted conidia germination rate where a reduction was expected. We hypothesize that during germination events, very small amounts of $\mathrm{H}_{2} \mathrm{O}_{2}$ are beneficial and necessary in the primordial germination- and hyphal extension events. It is known that $\mathrm{H}_{2} \mathrm{O}_{2}$ is necessary in de novo synthesis of cell wall and membrane components during germination and hyphal extension. Indirect evidence for this was provided by Seong et al (2008) who observed high activities of the peroxisomes at the onset of spore germination [31] The need for basal $\mathrm{H}_{2} \mathrm{O}_{2}$ is subscribed by the observation that catalase treatment results in a reduced spore germination at very early time points in germination. In several independent studies, it was demonstrated that reactive oxygen species such as $\mathrm{H}_{2} \mathrm{O}_{2}$ are key players and crucial in the regulation of cell differentiation in microbial eukaryotes 

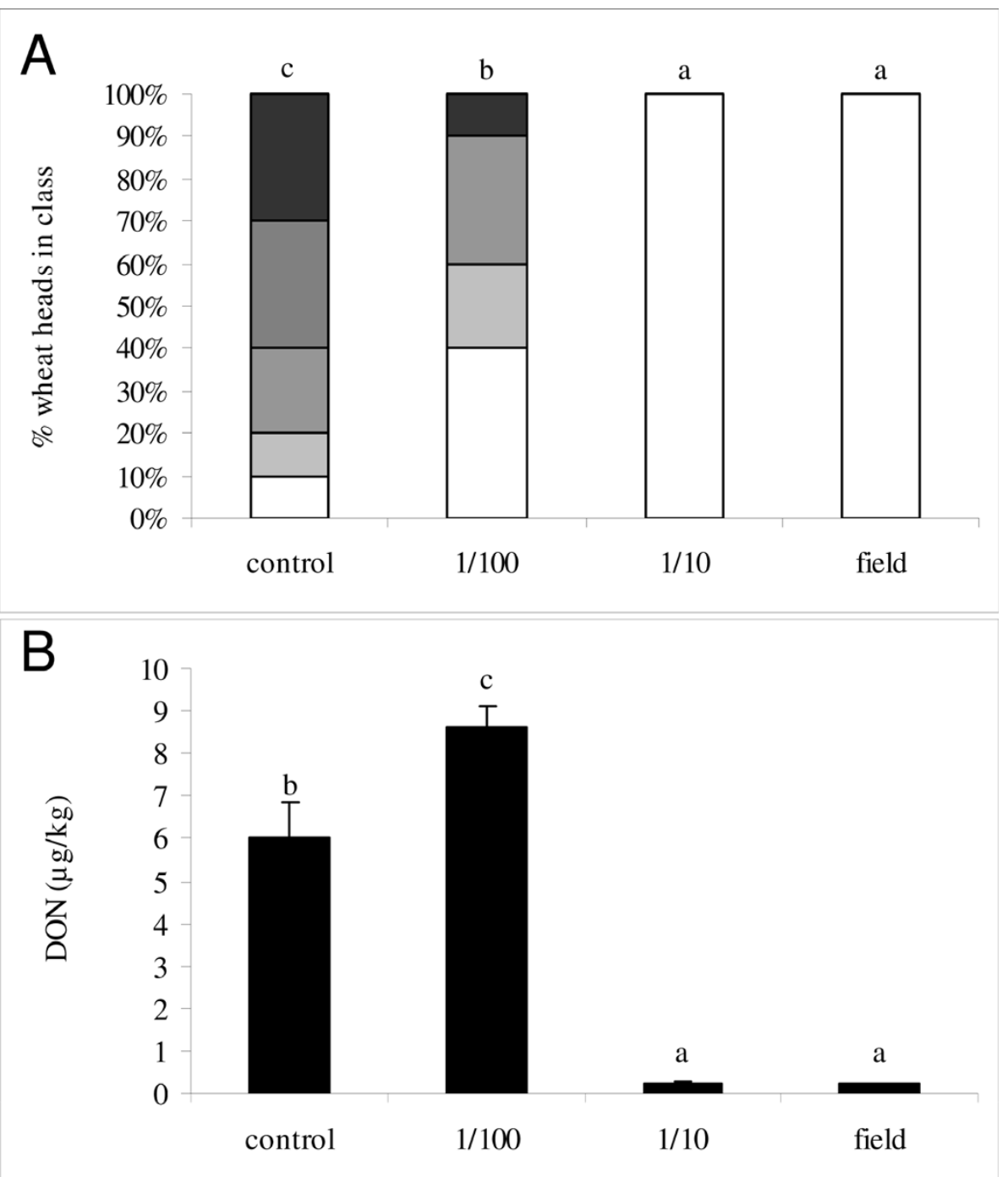

Figure 7 In vivo effect of prothioconazole + fluoxastrobin on symptoms of $F$. graminearum (a) and DON content (b) after point inoculation of wheat ears $\mathbf{1 4}$ days after infection. Wheat ears (variety Cadenza) were inoculated with two droplets of $20 \mu \mathrm{l}$ of conidia at a concentration of $10 e^{6}$ conidia/ml. Infection spots were indicated with a marker. Ears were subsequently treated with a tenfold dilution series of fluoxastrobin + prothioconazole starting from $0.5 \mathrm{~g} / \mathrm{l}+0.5 \mathrm{~g} / \mathrm{l}$. For each treatment, 10 plants were assessed for Fusarium symptoms. This experiment was repeated twice in time with analogous results. The figure represents one representative experiment. Different letters at each data point indicate differences from the control treatment after analysis with a Kruskall-Wallis and Mann-Whitney test with a sequential Bonferroni correction for multiple comparisons.

$[32,33]$. In accordance with this, it was demonstrated that NADPH oxidases which generate reactive oxygen are decisive in fungal cell differentiation and growth in a model system using Neurospora crassa [34].

Taken together, these results not only reinforce the hypothesis that $\mathrm{H}_{2} \mathrm{O}_{2}$ can induce DON biosynthesis but also suggest that DON accumulation induced by sub lethal triazole application is mediated through an increased production or release of $\mathrm{H}_{2} \mathrm{O}_{2}$ into the medium rendering a physiological interface of $\mathrm{H}_{2} \mathrm{O}_{2}$ influencing DON production. It is tempting to speculate on the mechanistics behind these observations. We hypothesize that due to the inhibition of ergosterol biosynthesis by the application of triazole fungicides, an increased cell permeability results in the increased release of $\mathrm{H}_{2} \mathrm{O}_{2}$ in the medium which in turns activates the trichothecene biosynthesis machinery. Indeed, although $\mathrm{H}_{2} \mathrm{O}_{2}$ is a very reactive molecule which can diffuse freely across bio membranes, it has been shown in a Sacharomyces model system that organisms prevent $\mathrm{H}_{2} \mathrm{O}_{2}$ diffusion $[35,36]$. This hypothesis is subscribed by accumulating indirect evidence in many other fungi. As such in 
Candida ergosterol depletion increases vulnerability to phagocytic oxidative damage [37]. In Sacharomyces it was demonstrated using ergosterol knock out mutants that ergosterol depletion results in a changed biophysical property of the plasma membrane leading to an increased permeability towards $\mathrm{H}_{2} \mathrm{O}_{2}$ [38].

Although beyond the scope of the present paper it is important to notice that triazole fungicides on their own can generate $\mathrm{H}_{2} \mathrm{O}_{2}$ in planta as an intermediate metabolite in plants through activation of antioxidant systems [39] generating as such a greening effect which results in a retardation of the senescence [40]. The effect of this physiological induced $\mathrm{H}_{2} \mathrm{O}_{2}$ in planta on DON production by an invading $F$. graminearum is till now not studied and certainly needs more attention in the future.

\section{Conclusions}

In the present work it was shown that sub lethal prothioconazole concentrations resulted in a significant increase in DON production by $F$. graminearum in a combined approach of an in vitro assay and an artificial infection trial. In the in vitro assay, the stimulated DON production was preceded by a prompt induction of $\mathrm{H}_{2} \mathrm{O}_{2}$ suggesting that the proliferated DON production was induced by an oxidative stress response in the fungus. This hypothesis was confirmed by exogenous application of catalase which abrogated the elevated DON production observed at the sub lethal doses of prothioconazole. In a broader framework, this work clearly shows that DON production by the plant pathogen F. graminearum is the result of the interaction of fungal genomics and external triggers. Further work is needed to characterise the effect of these external triggers influencing DON biosynthesis. This work will certainly lead to a better insight into factors that influence DON production under field conditions.

\section{Methods}

Fungal Material, induction of conidia, conidia suspension and conidia counting

A GFP transformant of Fusarium graminearum strain $8 / 1$ [41] was grown on potato dextrose agar (PDA) for 7 days at $20^{\circ} \mathrm{C}$ and kept at $4^{\circ} \mathrm{C}$ upon use in the germination assays. Conidia of $F$. graminearum were obtained by incubating a mycelium plug on a PDA plate for 7 days under a light regime of UV/darkness (12 h $365 \mathrm{~nm}$ $10 \mathrm{~W} / 12 \mathrm{~h}$ ). Macroconidia were harvested by adding distilled water amended with $0.01 \%$ of Tween 20 to the fully grown PDA plates and by rubbing the conidia-bearing mycelium with a spatula. Conidia were counted and diluted to a final concentration of $10 \mathrm{e} 6$ conidia/ml. In the germination assays, fungal conidia were visualised using a $0.02 \%$ cotton blue solution prepared in lactic acid.

\section{In vitro growth and germination assay, exogenous} application of fungicides and $\mathrm{H}_{2} \mathrm{O}_{2}$

In the present study, 3 fungicides were used i.e. fluoxastrobin+prothioconazole, azoxystrobin and prothioconazole. Field doses of each fungicide were the point of departure for the in vitro assay. The field dose of each fungicide differed according to the manufacturers instructions and mounted to $0.5 \mathrm{~g} / \mathrm{l}+0.5 \mathrm{~g} / \mathrm{l}, 0.83 \mathrm{~g}$ and $0.67 \mathrm{~g}$ for respectively fluoxastrobin+prothioconazole, azoxystrobin and prothioconazole.

In experiments aiming to measure fungal biomass and conidia germination, a ten-fold dilution series of these three fungicides was prepared to obtain a final concentration of $1 / 1000,1 / 100,1 / 10$ and field dose of each fungicide in the 24-well plates in which the assay was executed. In these wells, $250 \mu \mathrm{l}$ of conidial suspension was added and amended with $250 \mu \mathrm{l}$ of the fungicide dilution. These wells were incubated at $20^{\circ} \mathrm{C}$. Each treatment consisted out of 2 repetitions and the experiment was repeated three times independently in time. Control treatments consisted of $250 \mu \mathrm{l}$ of spore suspension and $250 \mu \mathrm{l}$ of distilled water.

$\mathrm{H}_{2} \mathrm{O}_{2}$ was applied once at the beginning of the germination trials in a final concentration ranging from 0.01 mM, $0.1 \mathrm{mM}, 1 \mathrm{mM}$ up to $10 \mathrm{mM}$. $250 \mu \mathrm{l}$ of $\mathrm{H}_{2} \mathrm{O}_{2}$ solution was added to $250 \mu \mathrm{l}$ of spore suspension. Each treatment consisted out of 2 repetitions and the experiment was repeated three times. Control treatments consisted of $250 \mu \mathrm{l}$ of spore suspension and $250 \mu \mathrm{l}$ of distilled water.

\section{Infection of wheat plants and application of fungicides in vivo}

F. graminearum macroconidia were obtained and harvested as previously described. A conidia suspension of $10 \mathrm{e} 6 \mathrm{conidia} / \mathrm{ml}$ was prepared. A dilution series of fluoxastrobin and azoxystrobin + prothioconazole was prepared starting from the field dose as mentioned in the in vitro assays. Ten ears of wheat plants at flowering stage (Zadok's stage 60) were infected with 2 droplets of $20 \mu \mathrm{l}$ of conidia suspension. Subsequently, the infected wheat plants were sprayed with fungicide dilutions till run off and placed in a growth chamber at $22^{\circ} \mathrm{C}$ under a relative humidity of $100 \%$ for 2 days to guarantee the conidial germination and penetration. After 2 days, the plants were incubated for 12 days in a growth chamber at $22^{\circ} \mathrm{C}$ under a light regime of $16 \mathrm{~h}$ light/ $8 \mathrm{~h}$ dark. Fourteen days after inoculation, the infection was assessed based on the surface of the ear covered with Fusarium symptoms: 1 = healthy; $2=$ up to $25 \% ; 3=25$ to $50 \% ; 4=50$ to $75 \% ; 5=75$ to $100 \%$ of the ear covered with symptoms. The experiment was repeated twice in time. 


\section{DNA extraction and fungal quantification using a Q-PCR approach}

To quantify the amount of Fusarium biomass in the in vitro assays, fungal biomass retrieved from each individual well was centrifuged and supernatant was eliminated. The pellet freeze-dried for $6 \mathrm{~h}$ at $-10^{\circ} \mathrm{C}$ and $4 \mathrm{~h}$ at $-50^{\circ} \mathrm{C}$ (Christ Alpha 1-2 LD Plus, Osterode, Deutschland). Samples were stored at $-20^{\circ} \mathrm{C}$ upon extraction.

DNA extraction was performed as previously described by Audenaert et al. (2009) [42] based on the method established by Shaghai and Mahroof et al. (1989) [43]. For PCR, amplification of the EF1 $\alpha$ gene, the forward primer FgramB379 (5'-CCATTCCCTGGGCGCT-3') and the reverse primer FgramB411 (5'CCTATTGACAGGTGGTTAGTGACTGG-3') were used [44]. The real-time PCR mix consisted of $12.5 \mu \mathrm{l} 2$ $\times$ SYBR Green PCR Master Mix (Stratagene), $250 \mathrm{nM}$ of each primer, $0.5 \mu \mathrm{g} / \mu \mathrm{l}$ bovine serum albumin (BSA) and $2 \mu \mathrm{l}$ of template DNA. PCR was performed on a 7000 series Detection System (Applied Biosystems) using the following PCR protocol: $2 \mathrm{~min}$ at $50^{\circ} \mathrm{C}, 10 \mathrm{~min}$ at $95^{\circ} \mathrm{C}$, 40 cycles of $95^{\circ} \mathrm{C}$ for $15 \mathrm{~s}$ and $62^{\circ} \mathrm{C}$ for $1 \mathrm{~min}$ followed by a dissociation analysis at $55^{\circ} \mathrm{C}$ to $95^{\circ} \mathrm{C}$.

A standard curve was established in threefold using a twofold dilution series of pure fungal DNA from $100 \mathrm{ng}$ up to $3.125 \mathrm{ng}$. The amount of fungal DNA was calculated from the cycle threshold $(\mathrm{Ct})$ and the amount of fungal material in control samples.

\section{Measurement of $\mathrm{H}_{2} \mathrm{O}_{2}$ and DON, application of catalase}

$\mathrm{H}_{2} \mathrm{O}_{2}$ formation in the fungicide experiments was measured $4 \mathrm{~h}, 24 \mathrm{~h}$ and $48 \mathrm{~h}$ post inoculation using a TMB (trimethylbenzidin) assay. This assay is based on the conversion of TMB to a blue stain upon reaction with $\mathrm{H}_{2} \mathrm{O}_{2}$ in the presence of peroxidases. $250 \mu \mathrm{l}$ of the conidia suspension was removed from a well and amended with an excess of $100 \mu \mathrm{l}$ horse radish peroxidase (500 $\mathrm{U} / \mathrm{ml})$ and $150 \mu \mathrm{l}$ of TMB $(1 \mathrm{mg} / \mathrm{ml})$. TMB was dissolved in $100 \%$ ethanol and the stock solution of $1 \mathrm{mg} /$ $\mathrm{ml}$ was prepared in $50 \mathrm{mM}$ of Tris-acetate buffer $(\mathrm{pH}$ 5.0). $\mathrm{H}_{2} \mathrm{O}_{2}$ formation was determined by measuring the absorbance at $620 \mathrm{~nm}$ in duplicate in each time point and in two independent experiments. In each experiment, a standard curve of pure $\mathrm{H}_{2} \mathrm{O}_{2}$ was added in a concentration range of $0.01 \mathrm{mM}$ up to $100 \mathrm{mM}$. The $\mathrm{H}_{2} \mathrm{O}_{2}$ formed in the in vitro assay was calculated based on this standard curve.

DON concentration was measured by ELISA using the Veratox DON 5/5 kit (Biognost, Neogen, Leest, Belgium). The lower limit of detection was $0.1 \mathrm{ppm}$. A standard curve was established using $0,0.25,0.4,1$ and $2 \mathrm{ppm}$ DON. The ELISA kit provides $100 \%$ specificity for DON. $200 \mu \mathrm{l}$ of the conidia suspension was removed from each well. Two repetitions per treatment were pooled and subsequently centrifuged to eliminate the fungal pellet. $100 \mu \mathrm{l}$ of this supernatant was used for further analysis in the ELISA assay. Experiments in which DON content was measured were repeated twice in time with two repetions per experiment and treatment. In the in vivo experiments, $1 \mathrm{~g}$ of grains was ground and extracted in $10 \mathrm{ml}$ of distilled water. Subsequently, the extract was analyzed by ELISA as described above. The DON content was measured in five fold.

In the in vitro experiments using catalase, $125 \mu \mathrm{l}$ of Catalase from bovine liver (Sigma, Bornem, Belgium) was added to the wells to a final concentration of 1000 $\mathrm{U} / \mathrm{ml}$. In the experiments where catalase was applied, $250 \mu \mathrm{l}$ of conidia were amended with $125 \mu \mathrm{l}$ of fungicides. Care was taken that the final concentration of the fungicides was the same as aforementioned in the other studies.

\section{Data analysis}

Differences in DON levels, $\mathrm{H}_{2} \mathrm{O}_{2}$ content, disease assessment, germination and fungal diameter were detected using a non-parametric Kruskall-Wallis and MannWhitney test with a sequential Bonferroni correction for multiple comparisons. Differences between DON levels and disease severity were considered at $\mathrm{P}=0.05 /(\mathrm{n}-1)$ with $\mathrm{n}$ the number of cases in the study. All data were analyzed using SPSS-software (Originally: Statistical Package for Social Sciences) version 15.0 for WindowsXP.

\section{Acknowledgements}

Kris Audenaert is a post-doctoral fellow of the University College Ghent research Fund. This work was carried out in the framework of a fund granted by the "Instituut voor de Aanmoediging van Innovatie door Wetenschap en Technologie Vlaanderen, project 5096) and the framework of the "Associatie onderzoeksgroep Primaire Plantaardige Productie en de Associatieonderzoeksgroep Mycotoxines en Toxigene Schimmels". We greatly acknowledge Dr. Karl Heinz Kogel (IPAZ institute, Giessen) for providing the $F$. graminearum strain.

\section{Author details}

'Department Biosciences and Landscape Architecture, Ghent University College/Ghent University Association, Schoonmeersstraat 52, B-9000 Gent, Belgium. 'Laboratory of Phytopathology, Faculty of Bioscience Engineering, Ghent University, Coupure Links 653, B-9000 Gent, Belgium. ${ }^{3}$ Laboratory of Food Analysis, Faculty of Pharmaceutical Sciences, Ghent Univeristy, Harelbekestraat 72, B-9000 Gent, Belgium.

\section{Authors' contributions}

KA conceived of the study, carried out most of the in vitro assays and drafted the manuscript. EC carried out the immunoassays and helped with the in vitro assays partim conidial germination. $\mathrm{GH}, \mathrm{MH}$ and SDS coordinated and helped to draft the manuscript. All authors read and approved the final manuscript.

Received: 18 December 2009 Accepted: 15 April 2010 Published: 15 April 2010 


\section{References}

1. Goswami RS, Kistler HC: Heading for disaster: Fusarium graminearum on cereal crops. Molecular Plant Pathology 2004, 5(6):515-525.

2. Bottalico A, Perrone G: Toxigenic Fusarium species and mycotoxins associated with head blight in small-grain cereals in Europe. European Journal of Plant Pathology 2002, 108(7):611-624.

3. Desjardins AE: Gibberella from A (venaceae) to Z (eae). Annual Review of Phytopathology 2003, 41:177-198.

4. Bai GH, Desjardins AE, Plattner RD: Deoxynivalenol-nonproducing Fusarium graminearum causes initial infection, but does not cause disease spread in wheat spikes. Mycopathologia 2002, 153(2):91-98.

5. Desmond OJ, Manners JM, Stephens AE, MaClean DJ, Schenk PM, Gardiner DM, Munn AL, Kazan K: The Fusarium mycotoxin deoxynivalenol elicits hydrogen peroxide production, programmed cell death and defence responses in wheat. Molecular Plant Pathology 2008, 9(4):435-445.

6. Mudge AM, Dill-Macky R, Dong YH, Gardiner DM, White RG, Manners JM: A role for the mycotoxin deoxynivalenol in stem colonisation during crown rot disease of wheat caused by Fusarium graminearum and Fusarium pseudograminearum. Physiological and Molecular Plant Pathology 2006, 69(1-3):73-85.

7. Hestbjerg $H$, Felding $G$, Elmholt S: Fusarium culmorum infection of barley seedlings: Correlation between aggressiveness and deoxynivalenol content. Journal of Phytopathology-Phytopathologische Zeitschrift 2002, 150(6):308-312.

8. Goswami RS, Kistler HC: Pathogenicity and in planta mycotoxin accumulation among members of the Fusarium graminearum species complex on wheat and rice. Phytopathology 2005, 95(12):1397-1404.

9. Liu WZ, Langseth W, Skinnes H, Elen ON, Sundheim L: Comparison of visual head blight ratings, seed infection levels, and deoxynivalenol production for assessment of resistance in cereals inoculated with Fusarium culmorum. European Journal of Plant Pathology 1997, 103(7):589-595.

10. Adams GC, Hart LP: The role of deoxynivalenol and 15acetyldeoxynivalenol in pathogenesis by Gibberella zeae as elucidated through protoplast fusions between toxigenic and non-toxigenic strains. Phytopathology 1989, 79(4):404-408.

11. Walker SL, Leath S, Hagler WM, Murphy JP: Variation among isolates of Fusarium graminearum associated with Fusarium head blight in North Carolina. Plant Disease 2001, 85(4):404-410.

12. Simpson DR, Thomsett MA, Nicholson P: Competitive interactions between Microdochium nivale var. majus, M-nivale var. nivale and Fusarium culmorum in planta and in vitro. Environmental Microbiology 2004, 6(1):79-87.

13. Schmidt-Heydt M, Magan N, Geisen R: Stress induction of mycotoxin biosynthesis genes by abiotic factors. Fems Microbiology Letters 2008, 284(2):142-149.

14. Gardiner DM, Kazan K, Manners JM: Nutrient profiling reveals potent inducers of trichothecene biosynthesis in Fusarium graminearum. Fungal Genetics and Biology 2009, 46(8):604-613.

15. Gardiner DM, Osborne S, Kazan K, Manners JM: Low pH regulates the production of deoxynivalenol by Fusarium graminearum. MicrobiologySGM 155(9):3149-3156

16. Magan N, Hope R, Colleate A, Baxter ES: Relationship between growth and mycotoxin production by Fusarium species, biocides and environment. European Journal of Plant Pathology 108(7):685-690.

17. Ponts $N$, Pinson-Gadais L, Verdal-Bonnin MN, Barreau C, Richard-Forget F: Accumulation of deoxynivalenol and its 15 -acetylated form is significantly modulated by oxidative stress in liquid cultures of Fusarium graminearum. FEMS Microbiology Letters 2006, 258(1):102-107.

18. Ochiai N, Tokai T, Takahashi-Ando N, Fujimura M, Kimura M: Genetically engineered Fusarium as a tool to evaluate the effects of environmental factors on initiation of trichothecene biosynthesis. FEMS Microbiology Letters 2007, 275(1):53-61.

19. Ponts N, Pinson-Gadais L, Barreau C, Richard-Forget F, Ouellet T: Exogenous $\mathrm{H} 2 \mathrm{O} 2$ and catalase treatments interfere with Tri genes expression in liquid cultures of Fusarium graminearum. FEBS Letters 2007, 581(3):443-447.

20. Ponts N, Couedelo L, Pinson-Gadais L, Verdal-Bonnin MN, Barreau C, Richard-Forget F: Fusarium response to oxidative stress by $\mathrm{H} 2 \mathrm{O} 2$ is trichothecene chemotype-dependent. FEMS Microbiology Letters 2009, 293(2):255-262.
21. Mullenborn C, Steiner U, Ludwig M, Oerke EC: Effect of fungicides on the complex of Fusarium species and saprophytic fungi colonizing wheat kernels. European Journal of Plant Pathology 2008, 120(2):157-166.

22. Ochiai N, Tokai T, Takahashi-Ando N, Fujimura M, Kimura M: Genetically engineered Fusarium as a tool to evaluate the effects of environmental factors on initiation of trichothecene biosynthesis. FEMS Microbiology Letters 275(1):53-61.

23. D'Mello JPF, Macdonald AMC, Postel D, Dijksma WTP, Dujardin A, Placinta CM: Pesticide use and mycotoxin production in Fusarium and Aspergillus phytopathogens. European Journal of Plant Pathology 104(8):741-751.

24. Covarelli L, Turner AS, Nicholson P: Repression of deoxynivalenol accumulation and expression of Tri genes in Fusarium culmorum by fungicides in vitro. Plant Pathology 2004, 53(1):22-28.

25. Matthies A, Buchenauer H: Effect of tebuconazole (Folicur (R)) and prochloraz (Sportak (R)) treatments on Fusarium head scab development, yield and deoxynivalenol (DON) content in grains of wheat following artificial inoculation with Fusarium culmorum. Zeitschrift für Pflanzenkrankheiten und Pflanzenschutz/Journal of Plant diseases and Protection 107(1):33-52.

26. Kim YS, Dixon EW, Vincelli P, Farman ML: Field resistance to strobilurin ( $Q$ (o)l) fungicides in Pyricularia grisea caused by mutations in the mitochondrial cytochrome b gene. Phytopathology 2003, 93(7):891-900.

27. Fisher N, Brown AC, Sexton G, Cook A, Windass J, Meunier B: Modeling the $\mathrm{Q}(\mathrm{o})$ site of crop pathogens in Saccharomyces cerevisiae cytochrome b. European Journal of Biochemistry 2004, 271(11):2264-2271.

28. Fraaije BA, Butters JA, Coelho JM, Jones DR, Hollomon DW: Following the dynamics of strobilurin resistance in Blumeria graminis f.sp tritici using quantitative allele-specific real-time PCR measurements with the fluorescent dye SYBR Green I. Plant Pathology 2002, 51(1):45-54.

29. Kaneko I, Ishii H: Effect of azoxystrobin on activities of antioxidant enzymes and alternative oxidase in wheat head blight pathogens Fusarium graminearum and Microdochium nivale. Journal of General Plant Pathology 2009, 75(5):388-398.

30. Levine $A$, Tenhaken $\mathrm{R}$, Dixon $\mathrm{R}$, Lamb $\mathrm{C}: \mathrm{H}_{2} \mathrm{O}_{2}$ from the oxidative burst orchestrates the plant hypersensitive disease resistance response. Cell 1994, 79(4):583-593.

31. Seong KY, Zhao X, Xu JR, Guldener U, Kistler HC: Conidial germination in the filamentous fungus Fusarium graminearum. Fungal Genetics and Biology 2008, 45(4):389-399

32. Aguirre J, Rios-Momberg M, Hewitt D, Hansberg W: Reactive oxygen species and development in microbial eukaryotes. Trends in Microbiology 2005, 13(3):111-118.

33. Hansberg W, Aguirre J: Hyperoxidant states cause microbial celldifferentiation by cell isolation from dioxygen. Journal of Theorethical Biology 1990, 142(2):201-221.

34. Cano-Dominguez N, Alvarez-Delfin K, Hansberg W, Aguirre J: NADPH oxidases NOX-1 and NOX-2 require the regulatory subunit NOR-1 to control cell differentiation and growth in Neurospora crassa. Eukaryotic Cell 2008, 7(8):1352-1361.

35. Branco MR, Marinho HS, Cyrne L, Antunes F: Decrease of $\mathrm{H}_{2} \mathrm{O}_{2}$ plasma membrane permeability during adaptation to $\mathrm{H}_{2} \mathrm{O}_{2}$ in Saccharomyces cerevisiae. Journal of Biological Chemistry 2004, 279(8):6501-6506.

36. Sousa-Lopes A, Antunes F, Cyrne L, Marinho HS: Decreased cellular permeability to $\mathrm{H}_{2} \mathrm{O}_{2}$ protects Saccharomyces cerevisiae cells in stationary phase against oxidative stress. FEBS Letters 2004, 578(12):152-156.

37. Shimokawa O, Nakayama H: Increased sensitivity of Candida albicans cells accumulating 14-alpha-methylated sterols to active oxygen: Possible relevance to in vivo efficacies of azole antifungal agents. Antimicrobial Agents and Chemotherapy 1992, 36(8):1626-1629.

38. Folmer V, Pedroso N, Matias AC, Lopes S, Antunes F, Cyrne L, Marinho HS: $\mathrm{H} 2 \mathrm{O} 2$ induces rapid biophysical and permeability changes in the plasma membrane of Saccharomyces cerevisiae. Biochimica Biophysica ActaBiomembr 2008, 1778(4):1141-1147.

39. Wu YX, von Tiedemann A: Impact of fungicides on active oxygen species and antioxidant enzymes in spring barley (Hordeum vulgare L.) exposed to ozone. Environmental Pollution 2002, 116(1):37-47.

40. Wu YX, von Tiedemann A: Physiological effects of azoxystrobin and epoxiconazole on senescence and the oxidative status of wheat. Pesticide Biochemistry and Physiology 2001, 71(1):1-10. 
41. Jansen C, von Wettstein D, Schafer W, Kogel KH, Felk A, Maier FJ: Infection patterns in barley and wheat spikes inoculated with wild-type and trichodiene synthase gene disrupted Fusarium graminearum. Proceedings of the National Academy of Sciences of the United States of America 2005, 102(46):16892-16897.

42. Audenaert K, Van Broeck R, Bekaert B, De Witte F, Heremans B, Messens K, Hofte M, Haesaert G: Fusarium head blight (FHB) in Flanders: population diversity, inter-species associations and DON contamination in commercial winter wheat varieties. European Journal of Plant Pathology 2009, 125(3):445-458.

43. Saghaimaroof MA, Soliman KM, Jorgensen RA, Allard RW: Ribosomal DNA spacer-length polymorphisms in barley: Mendelian inheritance, chromosomal location and population dynamics. Proceedings of the National Academy of Sciences of the United States of America-Biological Sciences 1984, 81(24):8014-8018.

44. Nicolaisen M, Supronien S, Nielsen LK, Lazzaro I, Spliid NH, Justesen AF: Real-time PCR for quantification of eleven individual Fusarium species in cereals. Journal of Microbiological Methods 2009, 76(3):234-240.

doi:10.1186/1471-2180-10-112

Cite this article as: Audenaert et al:: Hydrogen peroxide induced by the fungicide prothioconazole triggers deoxynivalenol (DON) production by Fusarium graminearum. BMC Microbiology 2010 10:112.

\section{Submit your next manuscript to BioMed Central and take full advantage of:}

- Convenient online submission

- Thorough peer review

- No space constraints or color figure charges

- Immediate publication on acceptance

- Inclusion in PubMed, CAS, Scopus and Google Scholar

- Research which is freely available for redistribution

Submit your manuscript at www.biomedcentral.com/submit 